\title{
SLC7A3: In Silico Prediction of a Potential New Cause of Childhood Epilepsy
}

\author{
Jo Sourbron ${ }^{1,9}$ Katrien Jansen ${ }^{1}$ Davide Mei ${ }^{2}$ Trine Bjørg Hammer ${ }^{3,4}$ Rikke S. Møller ${ }^{3,5}$ \\ Nina B. Gold ${ }^{6,8}$ Lauren O'Grady $^{6}$ Renzo Guerrini²,7 Lieven Lagae $^{1(1)}$
}

${ }^{1}$ Department of Development and Regeneration, Section Pediatric

Address for correspondence Lieven Lagae, PhD, MD, UZ Herestraat Neurology, University Hospital KU Leuven, Leuven, Belgium

2 Neuroscience Department, Meyer Children's Hospital, European 49, Box 7003, 3000 Leuven, Belgium Reference Network ERN EpiCARE, University of Florence, Florence, Italy

${ }^{3}$ Department of Regional Health Research, University of Southern Denmark, Odense, Denmark

${ }^{4}$ Epilepsy Genetics and Personalized Medicine, Danish Epilepsy Centre, Denmark and Clinical Genetic Department, Rigshospitalet, Copenhagen, Denmark

${ }^{5}$ Department of Epilepsy Genetics and Personalized Medicine, Danish Epilepsy Center Dianalund, Denmark

${ }^{6}$ Medical Genetics and Metabolism, Massachusetts General Hospital for Children, Boston, Massachusetts, United States

${ }^{7}$ IRCCS Stella Maris Foundation, Pisa, Italy

${ }^{8}$ Harvard Medical School, Department of Pediatrics, Boston, MA, USA

${ }^{9}$ Center for Medical Genetics, Ghent University Hospital, Ghent, Belgium (e-mail: lieven.lagae@uzleuven.be).

Neuropediatrics 2022;53:46-51.

\begin{abstract}
Keywords

- epilepsy

- case reports

- gene panel

- whole exome sequencing

- SLC7A3

We report an in-depth genetic analysis in an 11-year-old boy with drug-resistant, generalized seizures and developmental disability. Three distinct variants of unknown clinical significance (VUS) were detected by whole exome sequencing (WES) but not by initial genetic analyses (microarray and epilepsy gene panel). These variants involve the SLC7A3, CACNA1H, and IGLON5 genes, which were subsequently evaluated by computational analyses using the InterVar tool and MutationTaster. While future functional studies are necessary to prove the pathogenicity of a certain VUS, segregation analyses over three generations and in silico predictions suggest the X-linked gene SLC7A3 (transmembrane solute carrier transporter) as the likely culprit gene in this patient. In addition, a search via GeneMatcher unveiled two additional patients with a VUS in SLC7A3. We propose SLC7A3 as a likely candidate gene for epilepsy and/or developmental/cognitive delay and provide an overview of the 27 SLC genes related to epilepsy by other preclinical and/or clinical studies.
\end{abstract}

\section{Introduction}

Recent data underlines that genetic testing in childhood epilepsy can allow an accurate prognosis, impact management, likely limit the diagnostic odyssey, and possibly avoid further unnecessary testing. This is especially true in children with early-onset, drug-resistant epilepsy with neurodevelopmental disorders. ${ }^{1,2}$

received

March 4, 2021

accepted after revision

September 17, 2021

published online

December 6, 2021

Several genetic tests are currently available and widely used in clinic. The advantages and limitations of cytogenetics (karyotyping, microarray), gene panels, whole exome sequencing (WES), and whole genome sequencing (WGS) have recently been reviewed. ${ }^{3}$ Gene panel sequencing (most commonly by filtering WES data and including the analysis of both parents ["Trio"]) is currently the most applied, costeffective, and rapid test in clinic for diagnosing genetic

(c) 2021. Thieme. All rights reserved. Georg Thieme Verlag KG,

Rüdigerstraße 14,

70469 Stuttgart, Germany
DOI https://doi.org/ 10.1055/s-0041-1739133. ISSN 0174-304X. 
epilepsies. ${ }^{4}$ This approach has a high "read depth" or "coverage," meaning that this technique achieves a relatively high number of reads at a given base position. Due to this feature, nonsynonymous single nucleotide variants (SNVs), small intragenic deletions, duplications and flanking intronic sequences, as well as somatic variants have a higher probability to be detected. Conversely, WES would miss a variant that is poorly covered but has a higher "resolution" since it targets all the genes in our genome with an acceptable coverage in over $90 \%$ of the coding sequences. As a result, WES has largely contributed to the process of disease-gene identification. ${ }^{1,3}$ Interestingly, it has been shown that cytogenetic and sequencing analyses are complementary, and if one analysis does not yield positive results, the other one is often indicated. For example, up until now 27 genes, among those expressed in brain and belonging to the transmembrane solute carrier transporter (SLC) large family, have been related to patients with epilepsy (PWE). ${ }^{5}$ In most epilepsy gene panels, only few of these SLC genes known to be involved in epilepsy are included. So, the majority of SLC variants would not be detected, making WES an appropriate, additional approach.

In either case, WES has entered the clinical domain, ${ }^{1}$ and increasing research has been performed to investigate novel genes detected by WES. Even though functional studies using preclinical models are ultimately necessary to evaluate the pathogenicity of novel variants in vivo, ${ }^{6-8}$ in silico computational methods and segregation analyses can contribute to elucidate the potential role of the variants of unknown clinical significance (VUS). To point out, the InterVar tool generates an automated interpretation of any VUS by using 18 criteria, validated by the American College of Medical Genetics and Genomics (ACMG), ${ }^{9}$ and MutationTaster is able to further analyze SNVs, InDels and non-coding variants. ${ }^{10}$ More details about InterVar and MutationTaster can be found in the - Supplementary Material S1 (available online only). Using the segregation analysis in three different generations and the aforementioned in silico prediction models, we propose that the X-linked, WES-identified SLC7A3 variant is the possible genetic cause contributing to the etiology of epilepsy and developmental issues (motor and language) in our patient.

To reinforce the role of SLC7A3 in neurological disease, we have used GeneMatcher ${ }^{11}$ to unveil other patients with SLC7A3 variants. This had led to two additional patients with SLC7A3 variants who both show neurological problems including epilepsy and developmental problems.

\section{Original Case Report (1)}

An 11-year-old boy with a history of speech delay onset was referred to the University Hospitals Leuven at the age of 3 years due to difficult to treat epilepsy.

He was born by cesarean section at 37 weeks of uncomplicated gestation to nonconsanguineous parents. The birth weight was $3200 \mathrm{~g}$. During the first years of life, there were

Table 1 Variants of unknown significance reported in our patient analyzed by five computational analyses..$^{9,10}$ Deleterious thresholds are shown between brackets in the first row ${ }^{14,15}$

\begin{tabular}{|c|c|c|c|c|c|c|}
\hline Gene & $\begin{array}{l}\text { MutationTaster } \\
(>0.5)\end{array}$ & $\begin{array}{l}\text { CADD } \\
(>15)\end{array}$ & $\begin{array}{l}\text { SIFT } \\
(<0.05)\end{array}$ & $\begin{array}{l}\text { GERP }++ \\
(>4.4)\end{array}$ & $\begin{array}{l}\text { MetaSVM } \\
(>0.09)\end{array}$ & $\begin{array}{l}\text { Tools indicating } \\
\text { pathogenicity }\end{array}$ \\
\hline \multicolumn{7}{|l|}{ Case report 1} \\
\hline $\begin{array}{l}\text { ZNF335 } \\
\text { c. } 3023 C>G\end{array}$ & Benign, $p=0.999$ & 17.58 & 0.026 & 4.66 & -1.037 & $3 / 5$ \\
\hline $\begin{array}{l}\text { ZNF335 } \\
\text { c. } 3445 \mathrm{~A}>\mathrm{G}\end{array}$ & Pathogenic, $p=0.999$ & 25.1 & 0.001 & 4.86 & -1.108 & $4 / 5$ \\
\hline $\begin{array}{l}\text { CACNA1H } \\
\text { c. } 2264 \mathrm{G}>\mathrm{A}\end{array}$ & Benign, $p=0.999$ & ND & ND & ND & ND & $0 / 1$ \\
\hline $\begin{array}{l}\text { IGLON5 } \\
\text { c. } 8 \mathrm{C}>\mathrm{G}\end{array}$ & Benign, $p=0.996$ & 14.7 & 0 & 1.24 & -1.022 & $1 / 5$ \\
\hline $\begin{array}{l}\text { SLC7A3 (1) } \\
\text { c. } 1229 T>G\end{array}$ & Pathogenic, $p=0.999$ & 19.75 & 0.042 & 5.14 & 0.272 & $5 / 5$ \\
\hline \multicolumn{7}{|l|}{ Case report 2} \\
\hline $\begin{array}{l}S L C 7 A 3 \\
\text { c. } 107 A>G\end{array}$ & Pathogenic, $p=0.999$ & 27.6 & 3 & 4.84 & 0.906 & $4 / 5$ \\
\hline $\begin{array}{l}\text { ST8SIA4 } \\
\text { c. } 143 T>C\end{array}$ & Pathogenic, $p=0.999$ & 22.5 & 0.044 & 5.96 & -1.069 & $4 / 5$ \\
\hline \multicolumn{7}{|l|}{ Case report 3} \\
\hline $\begin{array}{l}S L C 7 A 3 \\
\text { c. } 244 C>A\end{array}$ & Pathogenic, $p=0.999$ & 26.4 & 0.002 & 4.7 & 0.919 & $5 / 5$ \\
\hline
\end{tabular}

MutationTaster $=$ conservation DNA sequence, splice site and mRNA stability prediction, protein features ( $p=$ probability); CADD $=63$ distinct variant annotation retrieved from Ensemble Variant Effect Predictor, data from the ENCODE project and information from UCSC genome browser tracks; SIFT = Protein sequence conservation among homologs; GERP $++=$ conservation DNA sequence by multispecies sequence alignment compared with the neutral expectation; MetaSVM = Ensemble scores based on Support Vector Machine. 
no medical issues despite delay in language development and psychomotor skills. At the age of 3 years, he experienced his first symmetric tonic seizure. When he turned 6 years, he also experienced clusters of tonic seizures and atypical absences. Physical examination, metabolic screening (-Supplementary Material S1, - Table S1 [available online only), and brain imaging studies (magnetic resonance imaging [MRI]) were unremarkable. EEG analyses showed a background with high-voltage generalized spikes and spike waves bilaterally with maximum amplitude in the frontal regions. During sleep, a marked increase in epileptiform activity was shown. Although multiple distinct antiseizure medications (ASM) were used, in mono- and/or polytherapy, our patient never experienced any seizure freedom. Currently, he is on ethosuximide and levetiracetam (LEV), due to which he did not experience any tonic seizures or atypical absences since the age of 8 years. However, short series of myoclonic seizures are still occurring in the limbs when he falls to sleep (duration \pm 1 second) on a daily/weekly basis. Regarding the family history, his father experienced a few seizures when he was a child. Nevertheless, he did not need ASM treatment and had a normal development and intelligence quotient (IQ).

Karyotype analysis, chromosomal microarray, investigations for GLUT1 deficiency (SLC2A1), myoclonic epilepsy with ragged red fibers (MERRF), and an epilepsy gene panel (IPG institute, Charleroi) were performed. The gene panel unraveled two VUS in the ZNF335 gene: c.3023C $>$ G (Pro1008Arg) and c.3445A $>$ G (Ile1149Val). The first VUS was inherited from the father and is present in the European control population (ExAC, 0.0015\%). The second VUS was inherited from the mother and is also present in the general control population (ExAC, 0.08\%). Even as four out of five prediction tools indicate that this latter VUS could be pathogenic (-Table 1), compound heterozygous (or homozygous) mutations in this gene have been linked to basal ganglia abnormalities, ${ }^{12}$ agyria with prominent extraaxial spaces, and cerebral/cerebellar hypoplasia or hypomyelination, ${ }^{13}$ which do not overlap with our patient's phenotype.

In the context of the ERN EpiCARE network, WES revealed three VUS: that is, CACNA1H (c.2264G > A), IGLON5 (c.8C > G), and SLC7A3 (c.1229T $>$ G). Pathogenicity prediction tools are summarized in - Table 1. The CACNA1H variant (inherited from the father) has been reported in the control population (66/265740 alleles, gnomAD). This is a synonymous (silent) variant for which splicing prediction algorithms predict no impact to the splice consensus sequence or the creation of a new splice site, and the nucleotide is not highly conserved. The IGLON5 mutation (de novo) has not been related to human disease and is reported in the control population (4/69228 alleles, gnomAD). The SLC7A3 variant has never been reported in the control population (gnomAD). Segregation of this SLC7A3 variant revealed that it was inherited from a healthy mother and was also present in the healthy maternal grandmother. The inheritance model of SLC7A3 is X-linked recessive (XLR), thus females can be healthy carriers and males can be affected. ${ }^{6}$

\section{Additional Case Report via GeneMatcher (2)}

A 13-year-old girl was referred to the Hillerød hospital (Denmark) at the age of 14 months due to febrile seizures (FS).

One month later, she had two afebrile seizures and treatment with valproic acid (VPA) was initiated. At the age of 4 years, she was seizure-free and tapered off VPA. At the age of 8 years, seizures reoccurred (clonic seizure) during a fever episode and again at age 11 years (two afebrile generalized tonic clonic seizures), for which treatment with LEV was started. Treatment was changed to eslicarbazepine (ESL) due to LEV-induced side effects. The EEG was normal during the first years of life. In contrast, at 11 years of age, her EEG showed epileptiform activity (spike-wave complexes [3 Hz]). Improvement on the EEG was seen after ASM treatment was started, and she has currently been seizure free for 2.3 years on ESL. Physical examination was normal. Metabolic screening and brain imaging studies (MRI at age 4 and 12 years) were normal. Further clinical details can be found in the -Supplementary Material S1 (available online only).

Regarding the family history, the father had one FS but was never diagnosed with epilepsy or neuropsychiatric disease.

Chromosomal microarray, fragile-X analysis, and WES were performed. WES revealed one VUS in the SLC7A3 gene $($ c.107A $>$ G) and one VUS in the ST8SIA4 gene (c.143T $>$ C) (-Table 1). Both variants (de novo) have never been reported in the control population (gnomAD). We cannot assure that neither SLC7A3 nor ST8IA4 are causative.

\section{Additional Case Report via GeneMatcher (3)}

A 2-year-old boy with a history of laryngeal cleft, tracheomalacia, feeding difficulties, poor weight gain, and speech and fine motor delay was referred to Massachusetts General Hospital (MGH, Boston, United States) at the age of 12 months due to feeding difficulties. Further clinical details can be found in the - Supplementary Material S1 (available online only).

Physical examination was unremarkable. Metabolic screening showed an increase of several amino acids (including arginine), although the significance of this finding remains uncertain. MRI showed asymmetry in size of the lateral ventricles at 11 months of age (left lateral ventricle larger than right lateral ventricle, potentially related to anatomic variation). EEG analyses showed normal sleep and awake EEG and no epileptiform abnormalities.

Regarding the family history, no epilepsy or developmental delay have been reported.

Chromosomal microarray was normal. WES revealed one VUS in the SLC7A3 gene (c.244 C > A), which was inherited from the patient's mother who never experienced any health issues (-Table 1).

\section{Discussion}

We report on the genetic analyses that we performed to find a possible new cause of childhood epilepsy and/or developmental issues. 
In our original case report (1), gene panels and WES detected five variants possibly related to the epilepsy in this patient. Epilepsy in ZNF335-related disease involves biallelic recessive mutations affecting the zinc finger protein that is crucial for methylation and expression of several brain specific genes. Initial genetic studies in our patient revealed a compound heterozygous state of the ZNF335 gene. However, computational analyses revealed that one of the two VUS are likely benign and the patient's phenotype did not overlap with those of reported PWE and ZNF335 mutations, showing clear brain anomalies such as microcephaly and/or invisible basal ganglia. ${ }^{12,13}$

Subsequently, WES revealed three VUS in three genes (IGLON5, SLC7A3, and CACNA1H). Our in silico predictions showed that the IGLON5 and CACNA1H variants are likely benign and also present in a healthy control population, in clear contrast to the SLC7A3 variant ( - Table 1). The CACNA1H variant was inherited from the father who experienced selflimiting seizures during childhood, thus we cannot exclude a modifier role of $C A C N A 1 H,{ }^{14}$ possibly another-yet unknown -gene with variable expression in father and son or a polygenetic cause. Whereas the SLC7A3 variant, follows a XLR inheritance pattern, ${ }^{6}$ which explains why female carriers in this family are not affected. However, the additional case report (2), which was found via GeneMatcher, is a girl with two VUS. The first VUS (in ST8IA4) is located on chromosome 5 and might be inherited in an autosomal recessive manner. Since we did not find a VUS in the other ST8IA4 gene, it would be more likely that the second VUS (in SLC7A3) contributes to the phenotype of our patient, because this gene is located on the X-chromosome, and skewed inactivation could lead to more expression of the potential pathogenic SLC7A3 in the brain, possibly leading to epilepsy and psychiatric issues. In the same manner, other X-linked genes (e.g., NEXMIF or IQSEC2) were initially discovered in $\mathrm{X}$-linked intellectual disability (XLID) families with unaffected carrier females, but later studies have shown that females could be affected as well. ${ }^{15,16}$

SLC7A3, or the cationic amino acid transporter (CT-3), is almost exclusively expressed in the brain and modulates arginine transportation in neurons. Defective SLC7A3 can affect NMDA and mammalian target of rapamycin (mTOR) signaling pathways that both are crucial in neuronal development, plasticity and epilepsy. Consistently, SLC7A3 mutations have clinically been ascribed to a few males with ASD, a neurodevelopmental disorder. ${ }^{6}$ Thus, a role of SLC7A3 also in epilepsy seems valid, which was present in 2 out 3 patients.

We have also summarized preclinical and/or clinical data of the 27 SLC genes that have linked to epilepsy (-Table 2). ${ }^{5}$ One of the most prevalent epilepsies related to SLC genes is Glut1 deficiency syndrome (Glut1DS), even though rare

Table 2 Solute carrier transporters (SLC) and their preclinical and clinical relevance to epilepsy

\begin{tabular}{|c|c|c|c|c|c|}
\hline SLC & Gene & Protein & Preclinical & Human (omim.org) & $\begin{array}{l}\text { Gene } \\
\text { panel }\end{array}$ \\
\hline 1 & SLC1A2/EAAT2 & $\begin{array}{l}\text { Excitatory amino acid } \\
\text { transporter } 2 \text { (glutamate) }\end{array}$ & Epilepsy & $\mathrm{EE}$ & Yes \\
\hline 2 & SLC1A4/ASCT1 & $\begin{array}{l}\text { Alanine/serine/cysteine } \\
\text { transporter } 1\end{array}$ & Schizophrenia & $\begin{array}{l}\text { EE, developmental delay, } \\
\text { microcephaly, severe ID }\end{array}$ & $\mathrm{No}^{\mathrm{b}}$ \\
\hline 3 & SLC2A1/GLUT1 & Glucose transporter 1 & $\begin{array}{l}\text { Epilepsy, metabolic } \\
\text { dysfunction }\end{array}$ & $\begin{array}{l}\text { GLUT1 deficiency syndrome, } \\
\text { infantile seizures, ID, } \\
\text { hypoglycorrhachia, } \\
\text { microcephaly }\end{array}$ & Yes \\
\hline 4 & SLC4A10/NBCn2 & $\mathrm{Na}^{+} / \mathrm{HCO} 3-$ cotransporter 2 & $\begin{array}{l}\text { Small brain ventricles, } \\
\text { reduced neuronal } \\
\text { excitation }\end{array}$ & Epilepsy, ID & $\mathrm{No}^{\mathrm{b}}$ \\
\hline 5 & SLC6A1/GAT1 & GABA transport protein 1 & Epilepsy & Myoclonic-atonic epilepsy & Yes \\
\hline 6 & SLC6A8/CrT & Creatine transporter & Cognitive deficits & $\begin{array}{l}\text { Cerebral creatine deficiency } \\
\text { syndrome }^{a}\end{array}$ & Yes \\
\hline 7 & SLC6A9/GlyT1 & $\begin{array}{l}\mathrm{Na}^{+} / \mathrm{Cl}^{-} \text {dependent glycine } \\
\text { transporter } 1\end{array}$ & $\begin{array}{l}\text { Epilepsy, } \\
\text { schizophrenia }\end{array}$ & Glycine encephalopathy & $\mathrm{No}^{\mathrm{b}}$ \\
\hline 8 & SLC6A11/GAT3 & GABA transport protein 3 & Epilepsy & $\begin{array}{l}\text { Epilepsy, ID, stereotypic } \\
\text { behavior }\end{array}$ & Yes \\
\hline 9 & SLC6A12/BGT1 & Betaine-GABA transporter 1 & No & Epilepsy & $\mathrm{No}^{\mathrm{b}}$ \\
\hline $10^{c}$ & SLC7A3/CAT3 & $\begin{array}{l}\text { Cationic amino acid } \\
\text { transporter } 3 \text { (Arg, Lys, Orn) }\end{array}$ & No & ASD, epilepsy (this report) & No \\
\hline 11 & SLC7A5/LAT1 & $\begin{array}{l}\text { L-type amino acid } \\
\text { transporter (neutral amino } \\
\text { acids) }\end{array}$ & Glioma & ASD & No \\
\hline 12 & SLC9A6/NHE6 & $\mathrm{Na}^{+} / \mathrm{H}^{+}$exchanger 6 & $\begin{array}{l}\text { Christianson } \\
\text { syndrome }\end{array}$ & $\begin{array}{l}\text { ID, X-linked syndromic, } \\
\text { Christianson type }{ }^{a}\end{array}$ & Yes \\
\hline
\end{tabular}


50 SLC7A3 Variant Involved in Epilepsy Sourbron et al.

Table 2 (Continued)

\begin{tabular}{|c|c|c|c|c|c|}
\hline SLC & Gene & Protein & Preclinical & Human (omim.org) & $\begin{array}{l}\text { Gene } \\
\text { panel }\end{array}$ \\
\hline 13 & SLC12A2/NKCC1 & $\begin{array}{l}\mathrm{Na}^{+}, \mathrm{K}+, 2 \mathrm{Cl}^{-} \\
\text {cotransporter } 1\end{array}$ & $\begin{array}{l}\text { Epilepsy } \\
\text { Stroke }\end{array}$ & Epilepsy & $\mathrm{No}^{\mathrm{b}}$ \\
\hline 14 & SLC12A5/KCC2 & $\mathrm{K}+-\mathrm{Cl}^{-}$cotransporter 2 & Epilepsy & Epilepsy & Yes \\
\hline 15 & SLC13A5/NaCT & $\mathrm{Na}^{+} /$citrate cotransporter & No & $\begin{array}{l}\text { Kohlschütter-Tönz syndrome a, } \\
\text { epilepsy }\end{array}$ & Yes \\
\hline 16 & SLC16A4/MCT4 & $\begin{array}{l}\text { Monocarboxylate } \\
\text { transporter } 4\end{array}$ & Glioma & Epilepsy & No \\
\hline 17 & SLC16A7/MCT2 & $\begin{array}{l}\text { Monocarboxylate } \\
\text { transporter } 2\end{array}$ & Epilepsy & Epilepsy & No \\
\hline 18 & SLC17A6/VGLUT2 & $\begin{array}{l}\text { Vesicular glutamate } \\
\text { transporter } 2\end{array}$ & Epilepsy & $\begin{array}{l}\text { Gnathodiaphyseal dysplasia, } \\
\text { tendinosis }\end{array}$ & No \\
\hline 19 & SLC23A3/SVCT3 & $\begin{array}{l}\mathrm{Na}^{+} \text {-dependent vitamin } \mathrm{C} \\
\text { transporter } 3\end{array}$ & No & Epilepsy & $\mathrm{No}^{\mathrm{b}}$ \\
\hline 20 & SLC25A12/AGC1 & $\begin{array}{l}\text { Aspartate glutamate } \\
\text { carrier } 1\end{array}$ & $\begin{array}{l}\text { Hypomyelination, } \\
\text { neuronal defects }\end{array}$ & EE, early infantile, ASD & $\mathrm{No}^{\mathrm{b}}$ \\
\hline 21 & SLC25A22/GC1 & $\begin{array}{l}\text { Mitochondrial glutamate } \\
\text { carrier } 1\end{array}$ & No & EE, early infantile & $\mathrm{No}^{\mathrm{b}}$ \\
\hline 22 & SLC25A39/CGI69 & $\begin{array}{l}\text { (Mitochondrial carrier } \\
\text { variety of solutes) }\end{array}$ & No & Childhood absence epilepsy & $\mathrm{No}^{\mathrm{b}}$ \\
\hline 23 & SLC25A42/MECREN & $\begin{array}{l}\text { (Mitochondrial carrier } \\
\text { variety of solutes) }\end{array}$ & No & $\begin{array}{l}\text { EE, metabolic crises with } \\
\text { variable encephalomyopathic } \\
\text { features and neurologic } \\
\text { regression }\end{array}$ & No \\
\hline 24 & SLC30A1/ZNT1 & Zinc transporter 1 & $\begin{array}{l}\text { Ischemic stroke Neo- } \\
\text { natal seizures }\end{array}$ & No & No \\
\hline 25 & SLC32A1/VGAT & Vesicular GABA transporter & $\begin{array}{l}\text { Epilepsy } \\
\text { Anxiety } \\
\text { Cortical dysplasia }\end{array}$ & No & No \\
\hline 26 & SLC35A3/AMRS & $\begin{array}{l}\text { (Nucleoside-sugar } \\
\text { transporter family) }\end{array}$ & No & $\begin{array}{l}\text { Epilepsy, ASD, Arthrogryposis, } \\
\text { mental retardation, and seizures }\end{array}$ & $\mathrm{No}^{\mathrm{b}}$ \\
\hline 27 & SLC55A1/LETM1 & $\begin{array}{l}\text { Leucine zipper-EF-hand } \\
\text { containing transmembrane } \\
\text { protein } 1 \text { (mitochondrial } \\
\text { cation/proton exchangers } \\
\mathrm{Ca}^{2+}, \mathrm{K}+, \mathrm{H}^{+} \text {) }\end{array}$ & No & Epilepsy & $\mathrm{No}^{\mathrm{b}}$ \\
\hline 28 & SLC62A1/ANKH & $\begin{array}{l}\text { Progressive ankylosis } \\
\text { protein homolog (ankylosis } \\
\text { homolog) (pyrophosphate } \\
\text { transporters) }\end{array}$ & No & Epilepsy & $\mathrm{No}^{\mathrm{b}}$ \\
\hline
\end{tabular}

Abbreviations: Arg, arginine; ASD, autism spectrum disorder; EE, epileptic encephalopathy; GABA, g-aminobutyric acid; ID, intellectual disability; Lys, lysine; Orn, Ornithine.

${ }^{a}$ characterized by several features such as epileptic seizures

bene variants related to epilepsy though not part of the IPG epilepsy gene panel (12/27 genes, i.e., 44\%)

' gene variant discovered in a patient with epilepsy by our case report.

(incidence of $\pm 4 / 100000$ births). ${ }^{17}$ Glut1DS should be considered in a patient with early onset absence epilepsy ( $<4$ years of age), myoclonic astatic epilepsy, absence epilepsies, or any epilepsy associated with a movement disorder. ${ }^{18}$ Early diagnosis of Glut1DS is confirmed by a low cerebrospinal fluid (CSF) glucose and a pathogenic SLC2A1 variant. This syndrome is of high clinical importance, since a very effective treatment (ketogenic diet) can improve or even reverse symptoms, especially if started promptly after diagnosis. ${ }^{17}$

Overall, our study on SLC7A3 variants shows that all patients had developmental issues-including motor skills and language development-and two out of three patients had epilepsy. Although SLC7A3 is a potential contributor to epilepsy and developmental problems, additional functional studies on Xenopus oocytes quantifying the cationic amino 
acid transportation are necessary to confirm the pathogenicity of SLC7A3 mutations. ${ }^{7}$

\section{Author Contributions}

All authors have made substantial contributions to conception and design, data acquisition, analysis and interpretation, and drafting the article. J.S.: conceptualization, methodology, formal analysis, investigation, resources, data curation, writing, visualization; K.J.: conceptualization, writing, supervision; D.M. and R.G.: formal analysis, conceptualization, investigation, resources, writing.

T.B.H., R.S.M., N.G., and L.O.: formal analysis, resources, data curation, writing; L.L.: conceptualization, investigation, writing, supervision.

Ethical Statements and Informed Consent We confirm that we have read the journal's position on issues involved in ethical publication and affirm that this report is consistent with those guidelines. Highest ethical standard was maintained during the study. Parents' informed consent was taken. All procedures performed in our study involving human participants were in accordance with the ethical standards of the institutional and/or national research committee and with the 1964 Helsinki Declaration and its later amendments or comparable ethical standards.

\section{Conflict of Interest}

L.L. received grants, and is a consultant and/or speaker for Zogenix; LivaNova, UCB, Shire, Eisai, Novartis, Takeda/Ovid, NEL, Epihunter. L.L. has a patent for ZX008 (fenfluramine) for the treatment of Dravet syndrome and infantile epilepsies assigned to his institution and licensed to Zogenix. The remaining authors have no conflict of interest to disclose.

\section{Acknowledgments}

The authors of this paper would like to thank the patients and their families for cooperating in the study, and for allowing their data to be used. We would also like to thank the ERN EpiCARE network. We did not receive any financial support for the research, authorship, and/or publication of this article.

\section{References}

1 Symonds JD, McTague A. Epilepsy and developmental disorders: Next generation sequencing in the clinic. Eur J Paediatr Neurol $2020 ; 24: 15-23$
2 Sisodiya SM, Whelan CD, Hatton SN, et al; ENIGMA Consortium Epilepsy Working Group. The ENIGMA-Epilepsy working group: Mapping disease from large data sets. Hum Brain Mapp 2020 (e-pub ahead of print). Doi: 10.1002/hbm.25037

3 Sands TT, Choi H. Genetic testing in pediatric epilepsy. Curr Neurol Neurosci Rep 2017;17(05):45

4 Mei D, Parrini E, Marini C, Guerrini R. The impact of nextgeneration sequencing on the diagnosis and treatment of epilepsy in paediatric patients. Mol Diagn Ther 2017;21(04): 357-373

$5 \mathrm{Hu}$ C, Tao L, Cao X, Chen L. The solute carrier transporters and the brain: Physiological and pharmacological implications. Asian J Pharm Sci 2020;15(02):131-144

6 Nava C, Rupp J, Boissel J-P, et al. Hypomorphic variants of cationic amino acid transporter 3 in males with autism spectrum disorders. Amino Acids 2015;47(12):2647-2658

7 Gilles W, Vulcu SD, Liewald JF, et al. Monovalent cation conductance in Xenopus laevis oocytes expressing hCAT-3. Biochim Biophys Acta 2005;1668(02):234-239

8 Siekierska A, Stamberger H, Deconinck T, et al; C4RCD Research Group AR working group of the EuroEPINOMICS RES Consortium. Biallelic VARS variants cause developmental encephalopathy with microcephaly that is recapitulated in vars knockout zebrafish. Nat Commun 2019;10(01):708

9 Li Q Wang K. InterVar: clinical interpretation of genetic variants by the 2015 ACMG-AMP Guidelines. Am J Hum Genet 2017;100 (02):267-280

10 Schwarz JM, Cooper DN, Schuelke M, Seelow D. MutationTaster2: mutation prediction for the deep-sequencing age. Nat Methods 2014;11(04):361-362

11 Sobreira N, Schiettecatte F, Valle D, Hamosh A. GeneMatcher: a matching tool for connecting investigators with an interest in the same gene. Hum Mutat 2015;36(10):928-930

12 Caglayan AO, Yaghouti K, Kockaya T, et al. Biallelic ZNF335 mutations cause basal ganglia abnormality with progressive cerebral/cerebellar atrophy. J Neurogenet 2020(November): $1-6$

13 Stouffs K, Stergachis AB, Vanderhasselt T, et al. Expanding the clinical spectrum of biallelic ZNF335 variants. Clin Genet 2018;94 (02):246-251

14 Calhoun JD, Huffman AM, Bellinski I, et al. CACNA1H variants are not a cause of monogenic epilepsy. Hum Mutat 2020;41(06): $1138-1144$

15 Mignot C, McMahon AC, Bar C, et al. IQSEC2-related encephalopathy in males and females: a comparative study including 37 novel patients. Genet Med 2019;21(04):837-849

16 Stamberger H, Hammer TB, Gardella E, et al. NEXMIF encephalopathy: an X-linked disorder with male and female phenotypic patterns. Genet Med 2021;23(02):363-373

17 Klepper J, Akman C, Armeno M, et al. Glut1 Deficiency Syndrome (Glut1DS): State of the art in 2020 and recommendations of the international Glut1DS study group. Epilepsia Open 2020;5(03): 354-365

18 Koch H, Weber YG. The glucose transporter type 1 (Glut1) syndromes. Epilepsy Behav 2019;91:90-93 